\title{
Variabilidade genética entre acessos do gênero Manihot por meio de marcadores moleculares ISSR
}

\author{
Kaliny Veiga Pessoa da Silva(1), Alfredo Augusto da Cunha Alves ${ }^{(2)}$, Maria Isabel Gomes Martins ${ }^{(3)}$, \\ Cláusio Antônio Ferreira de Melo $^{(4)}$ e Reginaldo de Carvalho(1)
}

\begin{abstract}
(1)Universidade Federal Rural de Pernambuco (UFRPE), Departamento de Biologia/Genética, Laboratório de Genética, Bioquímica e Sequenciamento de DNA, Avenida Dom Manuel de Medeiros, s/no, CEP 52171-900 Recife, PE. E-mail: kalinyveiga@hotmail.com, reginaldo.ufrpe@gmail.com ${ }^{(2)}$ Embrapa Labex-USA, USDA-ARS National Center for Genetic Resources Preservation, 1111, S. Mason St., Fort Collins, CO 80526, EUA. E-mail: alfredo.alves@embrapa.br (3)UFRPE, Programa de Pós-Graduação em Biotecnologia. E-mail: belgomes@gmail.com ${ }^{(4)}$ Universidade Estadual de Santa Cruz, Programa de Pós-Graduação em Genética e Biologia Molecular, Campus Soane Nazaré de Andrade, Km 16, Rodovia Ilhéus-Itabuna, CEP 45662-900 Ilhéus, BA. E-mail: clausiomelo@gmail.com
\end{abstract}

Resumo - O objetivo deste trabalho foi avaliar a diversidade genética intra e interespecífica de acessos de Manihot por meio de marcadores ISSR. Foram analisadas cinco espécies e duas variedades de Manihot, além de duas espécies do gênero Croton, utilizadas como grupo externo, por meio de 20 oligonucleotídeos iniciadores (Olii) ISSR UBC. Para análise do índice de similaridade entre as espécies e os acessos foram utilizados os coeficientes de Jaccard e de 'simple matching'. Os 20 Olii testados foram altamente polimórficos para todas as espécies analisadas, e $89,7 \%$ dos locus foram polimórficos. Há maior similaridade genética entre espécies diferentes de Manihot, como M. dichotoma var. undulata e M. caerulescens, do que entre indivíduos da mesma espécie, como M. dichotoma e M. dichotoma var. undulata.

Termos para indexação: germoplasma, diversidade genética, mandioca, polimorfismo.

\section{Genetic variation among accessions of the genus Manihot by ISSR markers}

\begin{abstract}
The objective of this work was to evaluate the genetic diversity within and among accessions of Manihot by using ISSR markers. Five species and two varieties of Manihot, besides two species of the genus Croton, used as the out-group, were analyzed by using 20 oligonucleotide (Olii) ISSR UBC primers. To analyze the similarity index between species and accessions, the Jaccard and simple matching coefficients were used. The 20 Olii tested were highly polymorphic in all species analyzed, and $89.7 \%$ of the loci were polymorphic. A higher genetic variability is observed among different species of Manihot, such as M. dichotoma var. undulata and M. caerulescens, than among individuals of the same species, such as M. dichotoma and M. dichotoma var. undulata.
\end{abstract}

Index terms: germplasm, genetic diversity, cassava, polymorphism.

\section{Introdução}

O gênero Manihot, originário do continente americano, abrange desde os Estados Unidos até a Argentina. São 98 espécies distribuídas em 19 seções, das quais 13 ocorrem no Brasil. A área abrangida pelo sul de Goiás e o oeste de Minas Gerais é considerada o maior centro de diversificação, seguido do sudeste do México, do Nordeste do Brasil, do sudeste do Mato Grosso e da Bolívia (Nassar, 1978, 2000). As espécies de Manihot podem ocorrer em todas as regiões tropicais e subtropicais do mundo e variam quanto ao padrão de crescimento, podendo assumir a forma de arbustos, subarbustos ou árvores (Umanah \& Hartmann, 1973).

A mandioca tornou-se uma das culturas alimentares mais importantes e difundidas no mundo, já que suas raízes são valiosa fonte de carboidratos. Tanto a parte aérea como as raízes tuberosas da mandioca podem ser aproveitadas para o consumo humano ou animal, na fabricação de farinha ou como parte da composição de diversos outros produtos e subprodutos. Sua utilização é especialmente intensa em países em desenvolvimento, onde as deficiências calóricas e a subnutrição são generalizadas. A mandioca pode ser classificada como de "mesa" ou mansa, também conhecida como macaxeira ou aipim, e é comumente consumida após cozimento, e apresenta baixo teor de ácido cianídrico, até 100 ppm. Outras cultivares com taxas maiores de cianeto ou mandiocas bravas são processadas artesanal ou industrialmente na fabricação de, principalmente, farinha e féculas (Fukuda et al.,1996; Valle et al., 2004). Assim, a mandioca é consumida por mais de 600 milhões de pessoas nas regiões tropicais e subtropicais do mundo (El-Sharkawy, 2006). 
O gênero Manihot apresenta variabilidade genética natural, o que favorece projetos de pesquisa que visam o melhoramento genético com a mandioca cultivada (Nassar \& Grattapaglia, 1986). Os marcadores moleculares são ferramentas eficazes no estudo dos genomas, pois detectam polimorfismos diretamente no DNA, não sofrem influência ambiental e são independentes do estádio de desenvolvimento da planta (Ferreira \& Grattapaglia, 2008). Em geral, os marcadores moleculares são baseados na amplificação de fragmentos de DNA por reação em cadeia da polimerase (PCR) e têm sido grandemente utilizados nos programas de melhoramento de plantas. Os marcadores podem ser usados, por exemplo, no estudo da diversidade genética de populações, na avaliação do potencial dos recursos genéticos disponíveis, na construção de mapas de ligação e na detecção de locus de caracteristicas quantitativas ("quantitative traits loci", QTLs) e de suas associações com características agronômicas (Benko-Iseppon et al., 2003).

A “inter simple sequence repeat" (ISSR) é uma técnica alternativa para estudar polimorfismos baseados em microssatélites, por meio dos genomas. O marcador molecular ISSR tem se mostrado uma poderosa ferramenta para análise da diversidade genética, bem como para a caracterização de acessos e cultivares de diversas espécies, como o cacau e espécies do gênero Solanum (Charters \& Wilkinson, 2000; Isshiki et al., 2008). Por se tratar de um marcador multiloco que não requer conhecimento prévio do DNA a ser avaliado (Gupta et al., 1994), o ISSR é uma técnica de baixo custo, de fácil uso e de grande reprodutibilidade (Matthews et al., 1999). O ISSR utiliza uma sequência simples repetida como oligonucleotídeo iniciador (Olii) para amplificar um fragmento de DNA delimitado por dois microssatélites invertidos, o que gera um alto nível de polimorfismo. Bornet \& Branchard (2004), ao utilizar nove Olii ISSRs, observaram diferentes níveis de polimorfismo entre Brassica e Arabidopsis, e maior abundância de sequências de microssatélites no genoma de Brassica.

O objetivo deste trabalho foi avaliar a diversidade genética intra e interespecífica de acessos de Manihot por meio de marcadores ISSR.

\section{Material e Métodos}

Foram avaliadas cinco espécies e duas variedades do gênero Manihot: M. esculenta Crantz var. cruvela; M. esculenta var. mandiocaba; M. caerulescens Pohl.; $M$. dichotoma Ule; $M$. dichotoma var. undulata Allem; e M. Alabellifolia Pohl.; todas provenientes da coleção de Manihot da Embrapa Mandioca e Fruticultura, Cruz das Almas, BA. Também foi avaliada uma espécie não publicada, identificada como $M$. noronhensis, do arquipélago de Fernando de Noronha, PE. Utilizou-se como material controle Croton fruticulosus Engelm. ex Torr. e C. rhamnifolius Willd.

Três a cinco folhas jovens, com peso entre $0,3 \mathrm{e}$ $0,5 \mathrm{~g}$, situadas no terço superior, foram coletadas de dois indivíduos de cada espécie para extração de DNA, conforme Doyle \& Doyle (1990). As amostras foram quantificadas em gel de agarose a $0,8 \%$ e visualizadas sobre luz ultravioleta. Aliquotas de $5 \mathrm{ng} \mu \mathrm{L}^{-1}$ foram retiradas para posterior utilização em reações de PCR.

Vinte Olii ISSR UBC - University of British Columbia -, (Tabela 1), foram amplificados via PCR segundo o protocolo de Bornet \& Branchard (2001), com algumas modificações: as reações de PCR foram conduzidas em volume final de $20 \mu \mathrm{L}$ contendo $0,4 \mathrm{U}$ de enzima Taq DNA polimerase, tampão da enzima $1 \mathrm{x}, 2,5 \mathrm{mmol} \mathrm{L}^{-1}$ de $\mathrm{MgCl}_{2}, 1 \mathrm{mmol} \mathrm{L}{ }^{-1}$ de dNTP, $50 \mu \mathrm{mol} \mathrm{L}^{-1}$ de iniciador e $25 \mathrm{ng}$ de DNA genômico. $\mathrm{O}$ programa consistiu de desnaturação inicial a $94^{\circ} \mathrm{C}$ por 4 min, seguido por 35 ciclos de desnaturação a $94^{\circ} \mathrm{C}$ por $30 \mathrm{~s}$, anelamento do Olii a $49,7-58^{\circ} \mathrm{C}$ (dependendo do Olii) por $35 \mathrm{~s}$ e extensão a $72^{\circ} \mathrm{C}$ por $2 \mathrm{~min}$, seguida de extensão final por $7 \mathrm{~min}$ a $72^{\circ} \mathrm{C}$. Os produtos amplificados por PCR foram corados com Sybr Green (LGC Biotecnologia Ltda., Cotia, São Paulo), separados por eletroforese em gel de agarose a 1,2\% em tampão de TAE 10X, e visualizados e fotografados sob luz ultra-violeta.

A partir dos produtos amplificados, foi construída uma matriz binária baseada na presença e ausência de bandas características de cada iniciador para cada um dos acessos. Para análise de similaridade, utilizou-se o coeficiente de Jaccard e de "simple matching", por meio do programa NTSYS-pc 2.1 (Rohlf, 2000), e o dendrograma foi construído com base no agrupamento estatístico UPGMA. O índice PCO também foi utilizado para análise comparativa, com uso do programa FAND 1.23 (Schlüter \& Harris, 2006), e as espécies foram agrupadas com base no coeficiente de

Pesq. agropec. bras., Brasília, v.46, n.9, p.1082-1088, set. 2011 
Jaccard. A análise de "bootstrap" foi realizada para 1.000 repetições, com uso do programa Winboot (Yap \& Nelson, 1996).

\section{Resultados e Discussão}

Os 20 oligonucleotídeos testados foram altamente polimórficos e amplificaram um total de 584 bandas (Tabela 1). O número de bandas variou de 13 a 48, nos Olii UBC 841 e UBC 810, respectivamente, que apresentaram entre 200 e $2.000 \mathrm{pb}$. O número total de locus foi 155 e variou de 3, nos Olii UBC 816 e 841, a 16, no UBC 810. Desse total, 99,3\% dos lócus foram polimórficos. O menor valor polimórfico ocorreu no Olii UBC 887. No entanto, em 15 dos 155 locus, o polimorfismo ocorreu exclusivamente em função da presença do grupo externo e, consequentemente, houve homogeneidade nesses locus para as espécies de Manihot (Tabela 1). Portanto, o polimorfismo existente entre os acessos avaliados do gênero Manihot foi de $89,7 \%$. Ao utilizar marcadores ISSR no estudo da variabilidade genética em etnovariedades de mandioca, Mühlen et al. (2000) obtiveram 97,96\% de Olii polimórficos e uma média geral de 4,5 alelos por loco.
Segundo Freitas et al. (2000), os resultados de estudos com marcadores obtidos para espécies cultivadas, como o trigo (similaridade média equivale a $73 \%$ ), mostraram menor índice de polimorfismo e estreita relação entre domesticação e similaridade genética entre variedades.

A similaridade genética apresentada pelo coeficiente de Jaccard, para as espécies do gênero Manihot, indicou maior proximidade entre $M$. dichotoma var. undulata $\mathrm{e}$ M. caerulescens $(0,5098)$, além de menor proximidade entre $M$. esculenta var. mandiocaba e $M$. dichotoma (0,3137) (Tabela 2). A análise de similaridade realizada por meio do coeficiente "simple matching" mostrou maior similaridade entre $M$. esculenta var. mandiocaba e $M$. esculenta var. cruvela $(0,6967)$, enquanto a menor relação de proximidade genética foi observada entre $M$. noronhensis e $M$. dichotoma $(0,5290)$. Nos dendrogramas gerados pelos dois coeficientes, foram formados três grupos distintos: duas espécies do grupo externo; M. caerulescens, $M$. dichotoma e $M$. dichotoma var. undulata; e $M$. esculenta var. mandiocaba, $M$. esculenta var. cruvela e M. flabellifolia (Figura 1). No entanto, M. noronhensis ficou excluída dos grupos formados, o

Tabela 1. Oligonucleotídeos iniciadores (Olii) ISSR UBC e temperatura de anelamento (Tm), número total de bandas, número total de locus, número de locus polimórficos e percentagem de polimorfismo.

\begin{tabular}{|c|c|c|c|c|c|c|}
\hline Olii & Sequência $\left(5^{\prime} 3^{\prime}\right)^{(1)}$ & $\operatorname{Tm}\left(\mathrm{C}^{\circ}\right)$ & № total de bandas & № total de locus & Locus polimórficos & Polimorfismo (\%) \\
\hline 809 & AGAGAGAGAGAGAGAGG & 52,8 & 44 & 10 & 10 & 100 \\
\hline 810 & GAGAGAGAGAGAGAGAT & 50,4 & 48 & 16 & 16 & $100^{(2)}$ \\
\hline 811 & GAGAGAGAGAGAGAGAC & 52,8 & 18 & 5 & 5 & 100 \\
\hline 812 & GAGAGAGAGAGA GAGAA & 50,4 & 20 & 5 & 5 & $100^{(2)}$ \\
\hline 815 & СТСТСТСТСТСТСТСТG & 52,8 & 20 & 4 & 4 & $100^{(2)}$ \\
\hline 816 & CACACACACACACACAT & 50,4 & 17 & 3 & 3 & $100^{(2)}$ \\
\hline 817 & CACACACACACACACAA & 50,4 & 18 & 5 & 5 & $100^{(2)}$ \\
\hline 818 & CACACACACACACACAG & 53,0 & 27 & 10 & 10 & $100^{(2)}$ \\
\hline 823 & ТСТСТСТСТСТСТСТСС & 51,0 & 42 & 9 & 9 & $100^{(2)}$ \\
\hline 825 & ACACACACACACACACT & 50,4 & 38 & 10 & 10 & $100^{(2)}$ \\
\hline 826 & ACACACACACACACACC & 52,8 & 24 & 5 & 5 & $100^{(2)}$ \\
\hline 827 & ACACACACACACACACG & 52,8 & 36 & 7 & 7 & 100 \\
\hline 828 & TGTGTGTGTGTGTGTGA & 50,0 & 20 & 7 & 7 & 100 \\
\hline 841 & GAGAGAGAGAGAGAGAYC & 52,0 & 13 & 3 & 3 & 100 \\
\hline 842 & GAGAGAGAGAGAGAGAYG & 54,0 & 34 & 9 & 9 & 100 \\
\hline 861 & ACCACCACCACCACCACC & 60,5 & 17 & 5 & 5 & $100^{(2)}$ \\
\hline 862 & AGCAGCAGCAGCAGCAGC & 58,0 & 35 & 7 & 7 & $100^{(2)}$ \\
\hline 864 & ATGATGATGATGATGATG & 51,9 & 27 & 10 & 10 & 100 \\
\hline 887 & DVDTCTCTCTCTCTCCT & 52,0 & 43 & 9 & 8 & 88,90 \\
\hline 888 & BDBCACACACACACACA & 52,0 & 43 & 10 & 10 & 100 \\
\hline Total & & & 584 & 155 & 154 & 99,30 \\
\hline
\end{tabular}

${ }^{(1)} \mathrm{D}, \mathrm{Y}$ e V significam oligonucleotídeos degenerados: $\mathrm{D}=(\mathrm{A}, \mathrm{G}, \mathrm{T})$; Y $=(\mathrm{C}, \mathrm{T})$; e V = (A, C, G). ${ }^{(2)}$ Polimorfismo ocorrido apenas em razão do grupo externo. 
que indica distância genética maior entre essa espécie e as demais analisadas no presente trabalho. Isso pode ser atribuído à distância geográfica existente entre essa espécie e as demais espécies do gênero, já que M. noronhensis foi introduzida na ilha de Fernando de Noronha, PE, onde pode ter adquirido diferenças adaptativas. A maior distância genética observada por Vieira et al. (2009), entre 32 variedades de mandioca, por meio de marcadores microssatélites, foi de 0,9100 . Esse resultado pode ser explicado pelo maior número de variedades analisadas e pelo fato de todas elas pertencerem a uma mesma espécie.

A análise de "bootstrap" foi realizada para verificar e dar suporte estatístico aos nós internos dos dendrogramas gerados por meio do método de agrupamento UPGMA. O dendrograma gerado a partir dos dados de similaridade de Jaccard (Figura 1) apresentou valores de "bootstrap" baixos (33,3, 40,7, 42,3 e $47,5 \%$ ). No entanto, a similaridade de $83,4 \%$, para M. esculenta var. mandiocaba e M. esculenta var. cruvela, dá maior suporte estatístico para a relação genética existente entre as espécies. Os valores de "bootstrap" obtidos no dendrograma gerado por meio do coeficiente de similaridade "simple matching" também foram baixos $(34,6,41,6$ e 47,3\%). Contudo, valores de similaridade maiores que $80,9,86,8$ e $98 \%$ também foram observados; este último para o nó entre as espécies de Croton. Assim, a análise de "bootstrap" observada entre os dois dendrogramas indica maior suporte estatístico para a árvore gerada por meio do cálculo do coeficiente de "simple matching" e do agrupamento UPGMA.

Ao se observar os dois coeficientes, a distância genética existente entre as variedades de $M$. esculenta e os dois acessos de $M$. dichotoma fica clara. As duas variedades de $M$. esculenta, cruvela e mandiocaba, aparecem muito próximas, por pertencerem à mesma espécie. Como estão agrupadas com M. flabellifolia, vários autores apontam essa espécie como provável ancestral da mandioca cultivada, com base no uso de marcadores moleculares (Olsen \& Schaal, 2001; Olsen, 2004). Outro fato que chamou a atenção foi a similaridade existente entre $M$. dichotoma var. undulata e $M$. caerulescens, que foi maior do que a similaridade entre $M$. dichotoma e $M$. dichotoma var. undulata, identificadas como sendo da mesma espécie, mas que apresentam diferenças botânicas marcantes quanto ao formato e ao tamanho dos frutos, das folhas, da

Tabela 2. Coeficiente de similaridade genética entre espécies do gênero Manihot e do grupo externo Croton pelos métodos de Jaccard e "simple matching". Sp.1, M. esculenta var. mandiocaba; Sp.2, M. noronhensis; Sp.3, M. esculenta var. cruvela; Sp.4, M. caerulescens; Sp.5, M. dichotoma; Sp.6, M. dichotoma var. undulata; Sp.7, M. flabellifolia; Sp.8, Croton fruticulosus; e Sp.9, C. rhamnifolius.

\begin{tabular}{|c|c|c|c|c|c|c|c|c|c|}
\hline Espécie & Sp.1 & Sp.2 & Sp.3 & Sp.4 & Sp.5 & Sp.6 & Sp.7 & Sp.8 & Sp.9 \\
\hline & \multicolumn{9}{|c|}{ Método de Jaccard } \\
\hline Sp.1 & 1,0000 & - & - & - & - & - & - & - & - \\
\hline Sp.2 & 0,3738 & 1,0000 & - & - & - & - & - & - & - \\
\hline Sp.3 & 0,5000 & 0,3962 & 1,0000 & - & - & - & - & - & - \\
\hline Sp.4 & 0,3551 & 0,3571 & 0,3644 & 1,0000 & - & - & - & - & - \\
\hline Sp.5 & 0,3137 & 0,3177 & 0,4062 & 0,4479 & 1,0000 & - & - & - & - \\
\hline Sp.6 & 0,3669 & 0,3684 & 0,3888 & 0,5098 & 0,4444 & 1,0000 & - & - & - \\
\hline Sp.7 & 0,4368 & 0,3963 & 0,419 & 0,3783 & 0,3921 & 0,4952 & 1,0000 & - & - \\
\hline Sp. 8 & 0,1744 & 0,1368 & 0,2142 & 0,1397 & 0,1585 & 0,1578 & 0,1720 & 1,0000 & - \\
\hline \multirow[t]{2}{*}{ Sp.9 } & 0,1702 & 0,1818 & 0,2065 & 0,15 & 0,1954 & 0,2142 & 0,1800 & 0,1639 & 1,0000 \\
\hline & \multicolumn{9}{|c|}{ Método "simple matching" } \\
\hline Sp.1 & 1,0000 & - & - & - & - & - & - & - & - \\
\hline Sp. 2 & 0,5677 & 1,0000 & - & - & - & - & - & - & - \\
\hline Sp.3 & 0,6967 & 0,5870 & 1,0000 & - & - & - & - & - & - \\
\hline Sp.4 & 0,5548 & 0,5354 & 0,5612 & 1,0000 & - & - & - & - & - \\
\hline Sp.5 & 0,5483 & 0,5290 & 0,6322 & 0,6580 & 1,0000 & - & - & - & - \\
\hline Sp.6 & 0,5548 & 0,5354 & 0,5741 & 0,6774 & 0,6451 & 1,0000 & - & - & - \\
\hline Sp.7 & 0,6258 & 0,5677 & 0,6064 & 0,5548 & 0,6000 & 0,6580 & 1,0000 & - & - \\
\hline Sp. 8 & 0,5419 & 0,4709 & 0,5741 & 0,4838 & 0,5548 & 0,4838 & 0,5032 & 1,0000 & - \\
\hline Sp.9 & 0,4967 & 0,4774 & 0,5290 & 0,4516 & 0,5483 & 0,5032 & 0,4709 & 0,6709 & 1,0000 \\
\hline
\end{tabular}


quantidade de látex e do porte da planta. $M$. dichotoma var. undulata e $M$. caerulescens apresentam maior semelhança morfológica.

Com base no coeficiente de Jaccard, também foi gerado o gráfico de distribuição em coordenadas principais (PCO), (Figura 2). Neste gráfico, assim como nos dois dendrogramas gerados, os acessos de
M. esculenta, cruvela e mandiocaba, aparecem muito próximos, e houve proximidade entre $M$. dichotoma var. undulata e M. caerulescens. Entretanto, observouse que as duas espécies do grupo externo são distantes entre si, com $C$. fruticulosus acima do eixo $\mathrm{Z}$ e C. rhamnifolius abaixo, com apenas 0,1639 de similaridade genética. M. caerulescens, M. dichotoma,
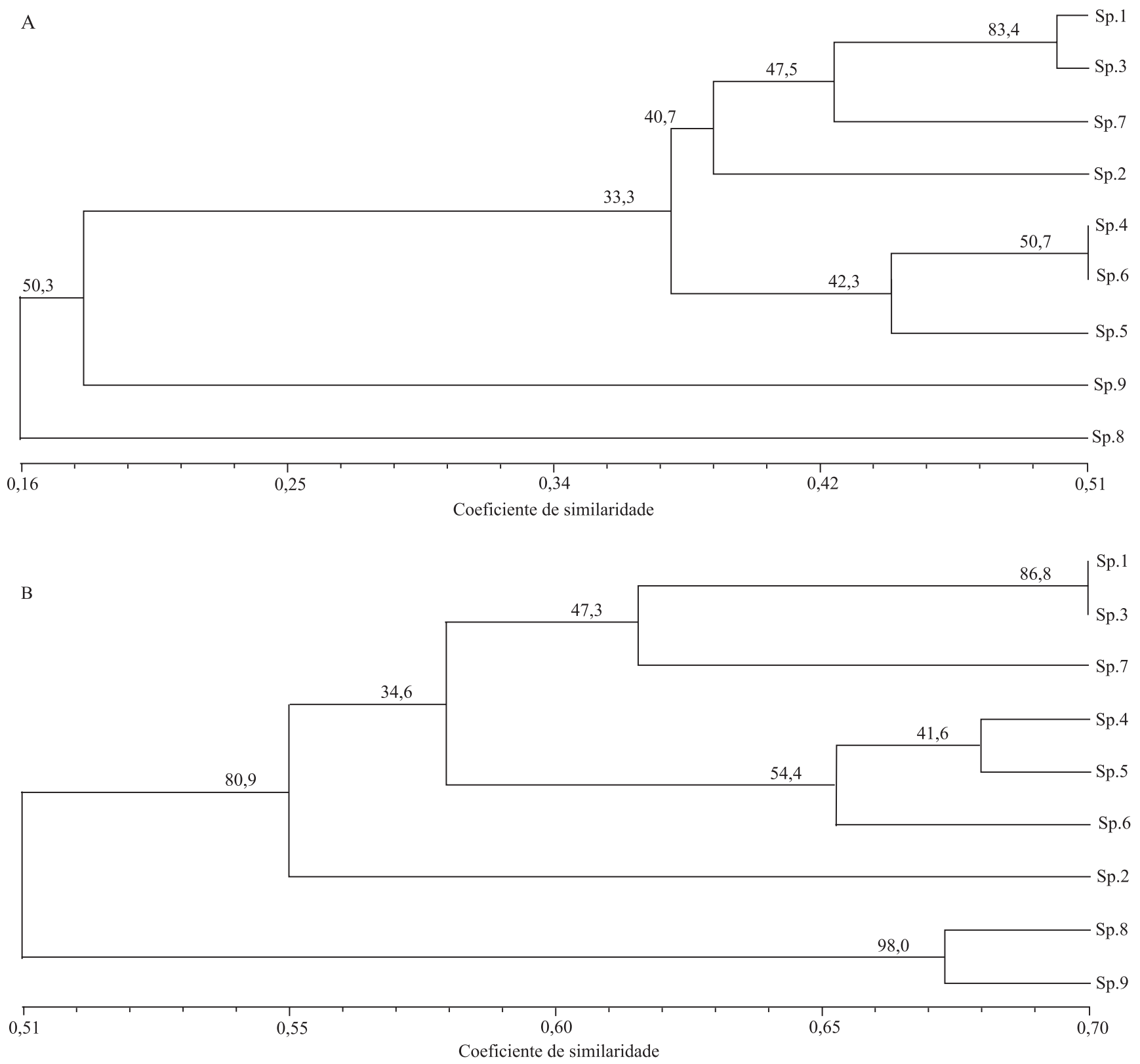

Figura 1. Dendrogramas obtidos pela análise das variações nas regiões ISSR das espécies de Manihot e Croton, por meio do coeficiente de Jaccard e do método de agrupamento UPGMA (A) e por meio do coeficiente de "simple matching" e do método de agrupamento UPGMA (B). Valores do "bootstrap" em percentagem para 1.000 repetições. Sp.1, M. esculenta var. mandiocaba; Sp.2, M. noronhensis; Sp.3, M. esculenta var. cruvela; Sp.4, M. caerulescens; Sp.5, M. dichotoma; Sp.6, M. dichotoma var. undulata; Sp.7, M. flabellifolia; Sp.8, Croton fruticulosus; e Sp.9, C. rhamnifolius. 
M. dichotoma var. undulata e M. flabellifolia estão dispostas no mesmo bloco, enquanto as variedades mandiocaba e cruvela estão agrupadas em outro bloco, sustentadas por um coeficiente de similaridade de Jaccard de 0,5.

Marcadores ISSR têm sido amplamente utilizados para detectar polimorfismos intraespecíficos em diversas espécies cultivadas, incluindo as do gênero Citrus e outras culturas, como amendoim e arroz (Pharmawati et al., 2004). Blair et al. (1999) obtiveram, em arroz, maior percentagem de fragmentos polimórficos com marcadores ISSR, em comparação a marcadores AFLP. Apesar de serem marcadores dominantes, os ISSR podem ser utilizados para analisar locus múltiplos em uma única reação (Goulão \& Oliveira, 2001) e para produzir fragmentos com grande reprodutibilidade, em comparação a outros marcadores com base em PCR não específico, como RAPD (Wolfe \& Liston, 1998). Para o gênero Manihot, a alta reprodutibilidade dos marcadores ISSR revelou claras divergências genéticas entre as espécies

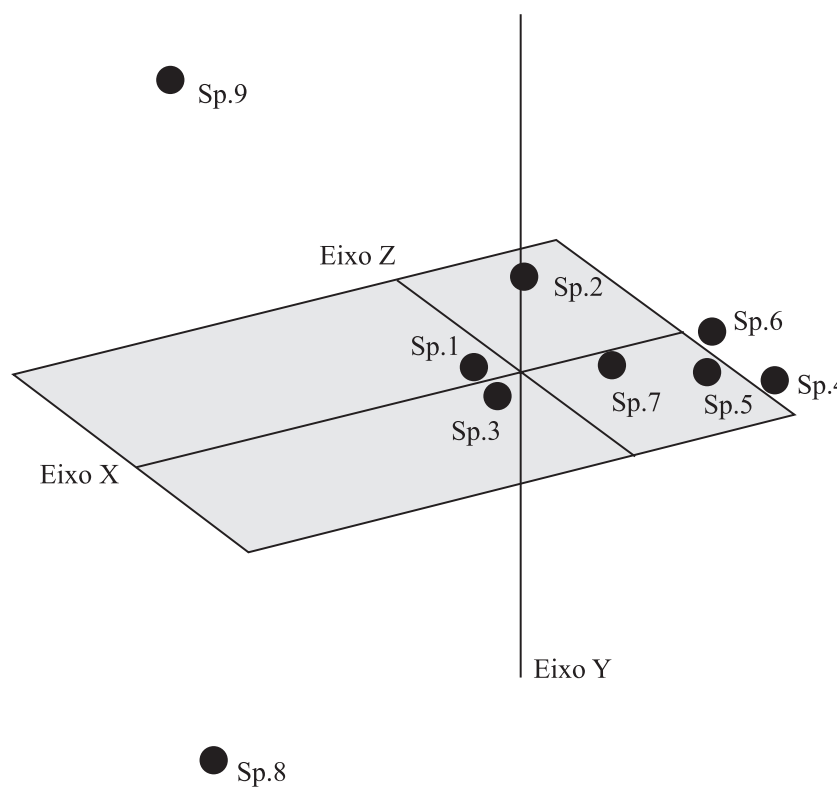

Figura 2. Análise de componentes principais com base no coeficiente de Jaccard, em espécies do gênero Manihot e Croton. Sp.1, M. esculenta var. mandiocaba; Sp.2, M. noronhensis; Sp.3, M. esculenta var. cruvela; Sp.4, M. caerulescens; Sp.5, M. dichotoma; Sp.6, M. dichotoma var. undulata; Sp.7, M. flabellifolia; Sp.8, Croton fruticulosus; e Sp.9, C. rhamnifolius. avaliadas no presente trabalho, tendo-se observado polimorfismo genético entre as variedades cultivadas e as demais espécies.

A utilização de dois coeficientes estatísticos, Jaccard e "simple matching", para avaliar o nível de similaridade genética, permitiu a comparação entre resultados e, consequentemente, aumentou sua confiabilidade, o que indica que tanto os dendrogramas, quanto o gráfico $\mathrm{PCO}$, seguiram a mesma linha no padrão de polimorfismo e que, embora a maioria dos trabalhos não utilize o "simple matching" para análise de dados binários, esse coeficiente, para Manihot, mostrou-se satisfatório.

\section{Conclusões}

1. Há divergências genéticas intra e interespecíficas entre os acessos de espécies de Manihot avaliadas, o que identifica, como eficiente, o marcador molecular ISSR.

2. Há maior similaridade genética entre diferentes espécies de Manihot, como M. dichotoma var. undulata e M. caerulescens, do que entre indivíduos da mesma espécie, como $M$. dichotoma e $M$. dichotoma var. undulata.

\section{Agradecimentos}

À Embrapa, pelo apoio financeiro; e à Universidade Federal Rural de Pernambuco, pela disponibilização da estrutura laboratorial.

\section{Referências}

BENKO-ISEPPON, A.M.; WINTER, P.; HÜTTEL, B.; STAGGINUS, C.; MÜHLBAUER, F.; KAHL, G. Molecular markers closely linked to Fusarium resistance genes in chickpea show significant alignments to pathogenesis-related genes located on Arabidopsis chromosomes 1 and 5. Theoretical and Applied Genetics, v.103, p.379-386, 2003.

BLAIR, M.W.; PANAUD, O.; MCCOUCH, S.R. Inter-simple sequence repeat (ISSR) amplification for analysis of microsatellite motif frequency and fingerprinting in rice (Oryza sativa L.). Theoretical and Applied Genetics, v.98, p.780-792, 1999.

BORNET, B.; BRANCHARD, M. Nonanchored inter simple sequence repeat (ISSR) markers: reproducible and specific tools for genome fingerprinting. Plant Molecular Biology, v.19, p.209-215, 2001.

BORNET, B.; BRANCHARD, M. Use of ISSR fingerprints to detect microsatellites and genetic diversity in several related Brassica taxa and Arabidopsis thaliana. Hereditas, v.140, p.245-248, 2004. 
CHARTERS. Y.M.; WILKINSON, M.J. The use of self-pollinated progenies as "in-groups" for the genetic characterization of cocoa germplasm. Theoretical and Applied Genetics, v.100, p.160-166, 2000 .

DOYLE, J.J.; DOYLE, J.L. Isolation of plant DNA from fresh tissue. Focus, v.12, p.13-15, 1990.

El-SHARKAWY, M.A. International research on cassava photosynthesis, productivity, eco-physiology, and responses to environmental stresses in the tropics. Photosynthetica, v.44, p.481-512, 2006.

FERREIRA, M.E.; GRATTAPAGLIA, D. Introdução ao uso de marcadores moleculares em análise genética. 3.ed. Brasília: Embrapa Cenargen, 2008. 220p. (Embrapa Cenargen. Documentos, 20).

FREITAS, L.B. de; JERUSALINSKY, L.; BONATTO, S.L.; SALZANO, F.M. Extreme homogeneity among Brazilian wheat genotypes determined by RAPD markers. Pesquisa Agropecuária Brasileira, v.35, p.2255-2260, 2000.

FUKUDA, W.M.G.; COSTA, I.R.S.; VILARINHOS, A.D.; OLIVEIRA, R.P. de. Banco de germoplasma de mandioca: manejo, conservação e caracterização. Cruz das Almas: Embrapa-CNPMF, 1996. 103p. (Embrapa-CNPMF. Documentos, 68).

GOULÃO, L.; OLIVEIRA, C.M. Molecular characterisation of cultivars of apple (Malus x domestica Borkh.) using microsatellite (SSR and ISSR) markers. Euphytica, v.122, p.81-89, 2001.

GUPTA, M.; CHYI, Y.-S.; ROMERO-seVERSON, J.; OWEN, J.L. Amplification of DNA markers from evolutionarily diverse genomes using single primers of simple-sequence repeats. Theoretical and Applied Genetics, v.89, p.998-1006, 1994.

ISSHIKI, S.; IWATA, N.; KHAN, M.R. ISSR variations in eggplant (Solanum melongena L.) and related Solanum species. Scientia Horticulturae, v.117, p.186-190, 2008.

MATTHEWS, D.; MCNICOLL, J.; HARDING, K.; MILLAM, S. 5'-anchored simple-sequence repeat primers are useful for analysing potato somatic hybrids. Plant Cell Reports, v.19, p.210-212, 1999.

MÜHLEN, G.S.; MARTINS, P.S.; ANDO, A. Variabilidade genética de etnovariedades de mandioca, avaliada por marcadores moleculares de DNA. Scientia Agricola, v.57, p.319-328, 2000.

NASSAR, N.M.A. Genetic resources of cassava: 4-chromosome behavior in some wild Manihot species. Indian Journal of Genetics and Plant Breeding, v.38, p.135-137, 1978.
NASSAR, N.M.A. Wild cassava Manihot spp.: biology and potentialities for genetic improvement. Genetics and Molecular Biology, v.23, p.201-212, 2000.

NASSAR, N.M.A.; GRATTAPAGLIA, D. Variabilidade de clones de mandioca em relação a fertilidade e aspectos morfológicos. Turrialba, v.36, p.555-559, 1986.

OLSEN, K.M. SNPs, SSRs and inferences on cassava's origin. Plant Molecular Biology, v.56, p.517-526, 2004.

OLSEN, K.M.; SCHAAL, B.A. Microsatellite variation in cassava (Manihot esculenta, Euphorbiaceae) and its wild relatives: further evidence for a southern Amazonian origin of domestication. American Journal of Botany, v.88, p.131-142, 2001.

PHARMAWATI, M.; YAN, G.; MCFARLANE, I.J. Application of RAPD and ISSR markers to analyse molecular relationships in Grevillea (Proteaceae). Australian Systematic Botany, v.17, p.49-61, 2004.

ROHLF, F.J. NTSYS-pc: numerical taxonomy and multivariate analysis system. Version 2.1. New York: Exeter Software, 2000. 98p.

SCHLÜTER, P.M.; HARRIS, S.A. Analysis of multilocus fingerprinting data sets containing missing data. Molecular Ecology Notes, v.6, p.569-572, 2006.

UMANAH, E.E.; HARTMANN, R.W. Chromosome numbers and karyotypes of some Manihot species. Journal of the American Society for Horticultural Science, v.98, p.272-274, 1973.

VALLE, T.L.; CARVALHO, C.R.L.; RAMOS, M.T.B.; MÜHLEN, G.S.; VILLELA, O.V. Conteúdo cianogênico em progênies de mandioca originadas do cruzamento de variedades mansas e bravas. Bragantia, v.63, p.221-226, 2004.

VIEIRA, E.A.; FIALHO, J. de F.; SILVA, M.S.; FUKUDA, W.M.G.; SANTOS FILHO, M.O.S. dos. Comportamento de genótipos de mandioca de mesa no Distrito Federal. Ciência Agronômica, v.40, p113-122, 2009.

WOLFE, A.D.; LISTON, A. Contributions of PCR-based methods to plant systematics and evolutionary biology. In: SOLTIS, D.E.; SOLTIS, P.S.; DOYLE, J.J. (Ed.). Molecular systematics of plants II: DNA sequencing. Boston: Kluwer Academic, 1998. p. $43-86$.

YAP, I.V.; NELSON, R.J. WINBOOT: a program for performing bootstrap analysis of binary data to determine the confidence limits of UPGMA-based dendrograms. Manila: International Rice Research Institute, 1996. 22p. (IRRI. Discussion paper, 14).

Recebido em 14 de junho de 2011 e aprovado em 26 de agosto de 2011 